\title{
Pero los nietos del jaguar aún estamos aquí Pedro Geoffroy Rivas, una crítica al humanismo eurocéntrico
}

Luis Alvarenga

E

I pensamiento del poeta y antropólogo Pedro Geoffroy Rivas (1908-1979) es una contribución importante para la reflexión - desde una perspectiva latinoamericana, es decir, no eurocéntrica- sobre la condición humana. El conjunto de su reflexión une varias perspectivas: la intuición poética de la realidad y el tiempo, el discurso científico de la antropología y la lin- güística y una relectura de la visión del mundo nahua, desde la perspectiva occidental. El hilo conductor es la superación del antihombre, expresada en su poema Vida, pasión y muerte del antihombre (1936,) y expuesta como crítica a una serie de elementos deshumanizantes (productores de "antihombres"), tanto de la cultura salvadoreña como de la cultura occidental.

\section{La antropología como punto de partida}

L

os estudios antropológicos de Pedro Geoffroy Rivas tuvieron lugar en la Universidad Autónoma de México entre 1950 y 1954, ${ }^{1}$ después de un largo recorrido político y una trayectoria poética considerable. ¿Por qué considerar esta vocación, cronológicamente tardía, como un punto de partida para aproximarnos al pensamiento humanista de Geoffroy? En buena medida, porque nos permite proponer una interpretación sobre el sentido de la búsqueda que emprende este autor en poemas, en sus ensayos, en el periodismo.

Sabemos que la antropología estudia al ser humano como problema ${ }^{2}$. Problemática es su vida, que no está predeterminada ni por los instintos ni por el destino. Es un proyecto que está por hacerse. Por 
tal razón, el poeta la define como "la ciencia del hombre y de sus obras $^{\prime \prime}$. Problemático es también su estudio, pues la antropología no goza de la comodidad de la que tienen otras ciencias, disponiendo de un objeto de estudio exterior al sujeto investigador. El ser humano es el investigador y es el investigado. Con todo y estas dificultades, la antropología — sea esta filosófica o científica, como en el caso de Geoffroy- es necesaria para plantearnos quiénes somos y cuál es el sentido de nuestra existencia.

"El estudio del hombre y de sus obras." Esta concepción, que parte del ser humano como una realidad dinámica (poética, podríamos decir, entendiendo inicialmente la poiesis como esa capacidad humana de crear cosas: de legar obras), es también una concepción que sugiere la necesidad de una antropología abierta a la multiplicidad cultural. En opinión de Geoffroy, hay una base importante: su teoría sobre el origen común de las civilizaciones. A través de un estudio comparativo de la astronomía nahua, china, hebrea, india, babilónica y griega, el poeta va encontrando grandes similitudes en la forma de designar las estrellas. "Viejos mitos, comunes a la mayor parte de los pueblos antiguos, sistemas religiosos, raíces idiomáticas semejantes, cosmogonías sorprendentemente idénticas, refuerzan cada día con mayor este concepto de un origen común para todas las civilizaciones" ${ }^{\prime 4}$, afirma. Hay, por tanto, confluencias en el origen de las civilizaciones. Luego, estas se desenvolverían en formas diferentes, merced a factores geográficos, sociológicos y de diversa índole. Una similar postura se puede advertir en los estudios que hace Geoffroy sobre "El problema del origen y evolución del lenguaje" y en "Origen y evolución de las lenguas romances". Ahora bien, el estudio de la lengua tiene, para Geoffroy, un carácter antropológico. A través de la lengua puede darse cuenta "del hombre y de sus obras". En otras palabras, el estudio lingüístico — desde una perspectiva que hoy Ilamaríamos interdisciplinar-, puede acercarnos a una manera de comprender al ser humano en su problematicidad.

\section{Trascendencia del estudio de la lengua}

En sus estudios sobre la "lengua salvadoreña" o sobre "el español que hablamos en El Salvador" rechaza cualquier pretensión normativa sobre el idioma. Más que imponer un paradigma de corrección del idioma, lo que interesa es acercarse a la lengua como fenómeno vivo y creativo. Así se lo hace saber a los miembros de la Academia Salvadoreña de la Lengua, en su discurso de incorporación a la misma: "Me he dedicado desde hace años al estudio del idioma, no en su aspecto académico, no conforme a las frías y rígidas normas filosóficas dentro 
de las cuales ha querido aprisionarse, desde la época de Dionisio de Tracia, el hablar del hombre, sino observando los cotidianos cambios que el pueblo - ese genial modificador de las lenguas- va introduciendo en ellas; registrando, apropiándome y usando los giros, las palabras, los vocablos que a diario se inventan en los mesones y en los caminos reales ${ }^{\prime \prime}$. En el prólogo a El español que hablamos en El Salvador, apunta: "Quienes luchan, inútilmente, por la 'conservación del idioma' olvidan que están frente a un fenómeno histórico, cambiante y multiforme, que sólo puede ser conservado cuando ha muerto. Porque el idioma vivo jamás puede aquietarse. Sufre infinitas variaciones, de un grupo a otro, dentro de cada grupo, en cada individuo, sin que ello signifique la pérdida de los contornos que lo caracterizan" ${ }^{\prime \prime}$. Podríamos plantear, así, lo que sostiene el filósofo austríaco Ludwig Wittgenstein: No hay una "esencia" del lenguaje, sino que los diferentes usos del lenguaje nos posibilitan tantas "formas de vida" como fuera posible. "Esto quiere decir —nos recuerda Geoffroy_que las mismas palabras pueden servir para que se ultrajen unas a otras las verduleras de los mercados y para que don Francisco de Quevedo haga exquisita poesía" ${ }^{\prime 7}$.

Esta riqueza humana del lenguaje viene dado, ciertamente, por algo que trasciende la perspectiva normativa o esencialista de la lengua, y que, más bien, reside en la relación de la lengua con la cultura - entendida esta en su sentido más amplio. La lengua tiene, además, una relación muy estrecha con el pensamiento: "Podemos entonces afirmar que el contenido del lenguaje está íntimamente ligado con la cultura, que cultura y lenguaje fluyen generalmente por cauces paralelos, y que el vocabulario de cada lengua refleja con gran fidelidad la cultura a cuyo servicio se encuentra esa lengua. Así, el lenguaje está estrechamente ligado a los hábitos de pensamiento. $Y$ no sólo ligado. En el fondo, probablemente, ambos son una sola cosa. La inagotable riqueza de la forma lingüística y la infinita variabilidad del proceso de pensamiento que constituye el contenido latente de todos los idiomas han sido siempre, en todas partes y en todo tiempo, la misma cosa: la grandiosa ciencia intuitiva de la expresión humana" ${ }^{\prime}$. Penetrar en la lengua es adentrarse "en la psicología de sus hablantes" ${ }^{\text {. }}$. En ese sentido, Geoffroy se acerca al relativismo lingüístico de Edward Sapir $^{10}$. El lingüista norteamericano - a quien cita en varios de sus escritos- sostiene que hay una relación importante entre cultura y lengua, y que, al haber una pluralidad de culturas, el enfoque del estudio lingüístico debe ser multicultural, en vez de elevar a canon una expresión lingüística determinada. En segundo lugar, Sapir arguye que hay una interrelación entre lenguaje y pensamiento. A través del lenguaje puede accederse a la visión de mundo de sus hablantes. 
Encontramos, por tanto, dos características de la condición humana: aunque la humanidad tenga un tronco común, pues somos integrantes de una misma especie: la humana, el desarrollo de esta especie ha dado frutos de una extraordinaria variedad. Ninguno de ellos puede valorarse como superior o inferior al otro. Antes bien, debe adoptarse una perspectiva multicultural. En el caso de la cultura salvadoreña, debemos comenzar por dialogar con una parte importante de nosotros mismos: nuestro sustrato nahua-pipil. Sin pretender adoptar una visión idealizada del pasado prehispánico, sin pretender sustituir la realidad cultural presente por la Arcadia de Tenochtitlan, es necesario abandonar la perspectiva eurocéntrica y entrar en franco diálogo con las raíces de nuestra lengua $y$, por tanto, de nuestra cultura y nuestra visión de mundo. Si comenzamos por eso, entonces el diálogo con otras culturas tendrá alguna posibilidad de ser fecundo.

\section{La visión poética del mundo: una relectura de la visión de mundo nahua}

Es necesario partir de la crítica de la tradición racionalista occidental. En su discurso de ingreso a la Academia Salvadoreña de la Lengua, Geoffroy lo dice de forma explícita: "Todo lo real es racional' ha repetido el hombre desde aquel malhadado día en que Aristóteles, envenenado de racionalismo por Sócrates, su maestro ${ }^{11}$, infiltró con deletéreas esencias todo eso que hemos dado en calificar como 'cultura occidental'. Durante miles de años, el hombre tuvo ante los ojos un esquema racional del mundo y de la vida, ubicándose a sí mismo en el centro de la creación, erigiéndose en medida de las cosas. Cientos, miles de vidas se perdieron en un inútil forcejeo por explicar, a la luz de la lógica aristotélica, lo que es por esencia inexplicable"12. Por lo tanto, esa modernidad racionalista está agotada en sus pretensiones de enseñorearse del "mundo de la vida" a través de sus categorías fijas e inmutables. "Ahora, de pronto, el hombre descubre que el mundo es completamente absurdo; que la verdadera realidad está detrás de la realidad que vemos, que oímos, que gustamos, en el diario hacer, en los triviales objetos familiares, en el paisaje de sobra conocido (...). Decidido por fin a vivir como lo que es realmente, el hombre lanza satélites exploratorios al infinito espacio de su subconsciente y trae hasta la pobre, descolorida y turbia cotidianidad de su prosa pequeños y deslumbrantes hallazgos. Algún día, rotas todas las amarras de la lógica racional, el hombre se hundirá entero en el absurdo para vivir plenamente su verdadera realidad. Porque habrá descubierto definitivamente que siempre ha tenido lo prodigioso al alcance de su ojo y de su mano"13. 
Para poder dar cuenta de esa "verdadera realidad", la intuición poética tiene ventajas sobre la categorización racionalista. Es, en ese sentido, que Geoffroy vuelve sus ojos a la cultura nahua-pipil, articulada con una visión de mundo poética, intuitiva y, por lo tanto, más vital: "Sin la ridícula pretensión de racionalizar el mundo y la existencia, esos pueblos prefirieron siempre elevar a los planos de la mágica poesía la creación del hombre y de las cosas"144, dice el poeta. Empero, esta visión no niega la facticidad. Simplemente se niega a buscar su esencia en la descripción de sus características exteriores o en la explicación de sus fenómenos. Busca trascender esa facticidad para buscar la vida que late en ella: "Todas las leyendas de la creación en los antiguos mitos mesoamericanos se refieren indudablemente a hechos históricos lejanísimos, a concretas realidades, a acontecimientos de un pasado perdido en la noche de los tiempos. Pero en ninguna de ellas se advierte un afán de histórica penetración, de establecimiento de fechas, nombres, lugares y sucesos. ¿Para qué buscar la extraviada realidad inmediata, si después de ella, imponiendo su avasalladora poesía, se iba dibujando con permanentes e indelebles caracteres esa otra realidad, mucho más aceptable, más creíble, precisamente por inverosímil y absurda?"15.

Por ello, su poesía de madurez recrea (no reproduce), recrea la visión poética del mundo nahua-pipil.
Para Geoffroy, esta visión intuitiva de la realidad resulta más fecunda. En el libro Yulcuicat/Versos, reelabora poéticamente los relatos cosmogónicos (explicación poética del problema del origen del mundo). Esta visión religiosa del mundo no está divorciada del ámbito cotidiano del ser humano. Hay una filosofía de la vida expresada en sus poemas. Tomemos por ejemplo, el poema "Breve lamento":

¿He de marcharme entonces? ¿Solo un instante viviré sobre el mundo?

¿Como la flor del tiempo, iré perdiendo pétalo tras pétalo? ¿Nada quedará entre vosotros?

Hasta las piedras finas se rompen. El oro se destruye.

Se rasgan las plumas preciosas.

¿Qué ha de hacer mi corazón entonces?

¿Nada será mi nombre alguna vez? ¿En vano he venido a la Tierra?

¡Oh, amigos!

No dejéis que perezca del todo.

¡Conservad este canto!16

La vida es frágil, efímera, pero perdura la obra humana —nuevamente volvemos a la definición que aporta Geoffroy sobre la antropología-. La obra humana, además, más frágil por excelencia: el canto, la poesía. Esa poesía que sirve, además, para celebrar esa fragilidad de la vida humana: 
¿Que corra el vino de hongos!

¿Que derramen la chicha sagrada!

Que el dorado licor de las palmeras

haga estallar el júbilo.

(...)

Para siempre nos iremos,

oh, Príncipes!

Todo lo dejaremos.

Las flores y los cantos

no pueden ser llevados al Reino de la Muerte.

Solo en la Tierra perdura su fragancia.

¡Aspirad el perfume!

¡Embriagaos!

En verdad nos iremos

dejando aquí los cantos y las flores! $!^{17}$
Ahora bien, parecería que Geoffroy se contradice cuando, por un lado, exalta la visión de mundo nahua-pipil que no se extravía en fijar fechas a los acontecimientos históricos para intuir su raíz vital $y$, por el otro, cuando, en tanto lingüista y antropólogo, utiliza el método científico que demanda la precisión en el dato. La contradicción es aparente. De lo que se trata es de ir más allá de los límites del racionalismo y caer en la cuenta de que la vida es sueño y racionalidad, es historia y es delirio, es número y es poesía.

\section{La superación del anti-hombre}

Partimos de la antropología de un Geoffroy maduro para concluir con la poesía de juventud de este autor. Es importante regresar a un poema suyo: Vida, pasión y muerte del anti-hombre, escrito en la penitenciaría central del Distrito Federal de México, cuando purgaba una condena por participar en el incendio de la embajada salvadoreña como protesta por el reconocimiento diplomático que Maximiliano Hernández Martínez otorgó a la dictadura de Franco ${ }^{18}$. Suele interpretársele como un poema que explica la evolución ideológica del autor, sobre todo en la quinta parte:

Vivíamos sobre una base falsa, cabalgando en el vértice de un asqueroso mundo de mentiras, trepando en andamios ilusorios, fabricando castillos en el aire, inflando vanas pompas de jabón, desarticulando sueños. ${ }^{19}$

El poeta burgués, que vive sobre una base falsa, despierta al dolor de los desposeídos. Deja de ser un "pobrecito poeta" y emprende un tortuoso camino hacia su transformación. Hablar de un antihombre y de una transformación de éste remite a Nietzsche, como ya lo demostró Rafael Lara Martínez. El "pobrecito poeta" muere en vida, baja a los infiernos y luego se levanta de entre los muertos,

Violento, desatado, como un huracán recién parido, colgado de mi angustia, despeñado en mis ímpetus, con los ojos cuajados de asombro y 
la palabra apenas murmurada, dejando todavía acre sabor de sangre entre los labios,

cargado con el enorme peso de la respuesta única,

ardido en los crisoles de hondos regocijos,

resurrecto en la alegría fecunda y madrugada

que puso en mi cariño dos radiosas auroras proletarias ${ }^{20}$.

Esta transformación, de antihombre, de "pobrecito poeta" a ese huracán desatado con los ojos cuajados de asombro se asemeja a la transformación que señala Nietzsche: el hombre moderno debe dejar de ser bestia de carga, para luego convertirse en león y finalmente, devenir en niño. Seguimos hasta ahí a Lara Martínez. La hermosa violencia descrita en ese "huracán recién parido", semejante a un niño en la inocencia y la vitalidad, sería el rasgo del nuevo ser, del super-hombre nietzscheano, pero encarnado en la lucha de los oprimidos.

Ahora bien, esta transformación puede admitir otra lectura. La base falsa, el "vértice de un asqueroso mundo de mentiras", los "castillos en el aire" son algo más que la enajenación burguesa. Son los ensueños del racionalismo moderno, que produce anti-hombres y pobrecitos poetas. El despertar a las transformaciones $-\mathrm{O}$ a la nietzschena "transvaloración de los valores" significa "bajar" a los "infiernos" de todo aquello que niega ese racionalismo: el "hombre en toda su terrible verdad/ en su espantosa y sublime verdad" ${ }^{\prime 21}$.

Esa verdad, sublime y espantosa a la vez, no es ajena a la intuición poética. Es necesario, pues, pasar por todo ese trance y resucitar convertido en niño o en huracán.

Ello obliga, por tanto, a reconsiderar el tiempo histórico de una manera distinta de lo que ha hecho el racionalismo moderno. Es necesario, con la poesía, traer a la memoria la eterna historia de los "hijos del jaguar", que somos todos:

anduvimos errantes

años años años anduvimos errantes la ventisca el granito los violentos vendavales

las grandes bestias devoradoras nada pudo detener nuestros pasos ${ }^{22}$.

Las peregrinaciones circulares de la cultura nahua se traen al presente, pues tienen mucho que decirnos, a los hombres y mujeres de ahora. Nos dicen que somos una cultura peregrina. Los nietos del jaguar siguen, seguimos, andando errantes, buscando un destino que creemos ser la tierra prometida, aunque quizá el tesoro sea la peregrinación misma. Pero esa peregrinación no es hacia el norte o el sur. Es a la tierra de la que venimos. Cuando el poeta afirma: "Pero los nietos del jaguar estamos aquí", se está afirmando que nuestro humanismo debe fundarse en la espera, que no es espera pasiva, sino esperanza activa: la esperanza del que busca y lucha por su tierra prometida. En otras palabras: 


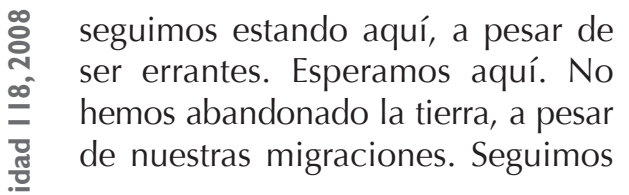

Notas

1 Cfr. Norma Cisneros de Reyes, "Pedro Geoffroy Rivas", en Taller de Letras, nos. 79-80, San Salvador, 1985.

2 En esto, sigo la argumentación de José David García Bacca y Carlos Beorlegui. Ver, de este último autor, Antropología filosófica. Nosotros: urdimbre solidaria y responsable, Universidad de Deusto, Bilbao, 1999 , p. 35 y ss.

3 Ver “¿Qué es la antropología”, en La mágica raíz, Dirección de Publicaciones e Impresos, 1998, p. 19.

4 "Origen común de las civilizaciones”, en Op. cit., p. 15.

5 Cfr. "Discurso pronunciado en la Academia Salvadoreña de la Lengua”, en Op. cit., pp. 65 y 66.

6 Prólogo a El español que hablamos en El Salvador, San Salvador, 1969, pp. 3 y 4 .

7 Ibídem, p. 4.

$8 \quad$ Ibídem, p. 5.

9 Ídem.

10 Ver María Xosé Fernández Casas, "El relativismo lingüístico de Edward Sapir: Una revisión de tópicos infundados", en Teorema, Vol. $\mathrm{XXI} / 3,2003$, pp. 115-129. esperando esa tierra:

pero aún estamos aquí

y otra vez ganaremos la tierra

para los nietos del jaguar ${ }^{23}$.

11 La frase es de Hegel. La referencia de Aristóteles quizá haga alusión en realidad a Platón, quien efectivamente fue discípulo de Sócrates.

12 "Discurso pronunciado en la Academia Salvadoreña de la Lengua”, en Op. cit., p. 67.

13 Ibíd., pp. 67-68.

14 Ibíd., p. 69.

15 Ídem.

16 Ver Yulcuicat, pp. 35-36; Versos, pp. 31-32.

17 "Canto de primavera", en Yulcuicat, p. 26 y en Versos, pp. 23 y 24.

18 Entrevista con José María Cuéllar, publicada en Letraviva, suplemento del periódico El Universitario, de la Universidad de El Salvador, San Salvador, 30 de agosto de 1979, p. 2.

19 Cfr. Vida, pasión y muerte del antihombre, Dirección de Publicaciones e Impresos, San Salvador, 1978, p. 15.

$20 \quad$ Ibídem, p. 17.

21 Ibídem, p. 16.

22 "Cuenta de la peregrinación”, en Los hijos del jaguar, Editorial Universitaria, San Salvador, 1979, p. 13.

23 "Para los nietos del jaguar", en Op. cit., p. 